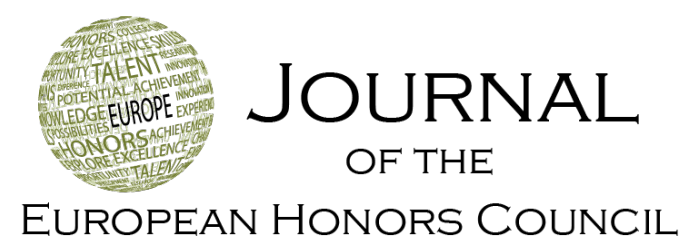

Note

\title{
Remote teaching transition during COVID-19 - the first five weeks and the start of a digital knowledge-building community
}

Marca Wolfensberger ${ }^{1 *}$ \& Ning Ding ${ }^{2}$

$1 \quad$ Hanze University of Applied Sciences Groningen and Utrecht University, the Netherlands; m.v.c.wolfensberger@pl.hanze.nl

$2 \quad$ Hanze University of Applied Sciences Groningen, the Netherlands; n.ding@pl.hanze.nl

*Correspondence: $\underline{\text { m.v.c.wolfensberger@pl.hanze.nl }}$

Received: 21 May 2020; Accepted: 16 September 2020; Published: 21 September 2020

Keywords: knowledge-building community; remote teaching; COVID-19

\section{Introduction}

The COVID-19 pandemic forces millions of teachers worldwide to engage in online teaching. Teachers are exploring and experimenting with various digital forms to deliver learning content, keep communicating with students and colleagues, and assess learning outcomes. A digital knowledge-building community gradually emerges and becomes more vivid. This note reports results from a study among honors teachers and administrators from 18 schools of a large Dutch university who all shared their problems and recommendations after the first five weeks of remote teaching, Spring 2020.

To understand the context of the study, we explain the measures taken in Dutch higher education because of the COVID-19 pandemic. We then turn to the concept of the knowledge-building community, zoom into the community aspect of this knowledge-building community, and reflect on the specific role of honors programs. Then, we report on the data collection and preliminary results of the study. Finally, we share conclusions and suggestions for further research.

\section{Measures in Dutch higher education because of the COVID-19 pandemic (March-May 2020)}

On Thursday March 12, 2020, the Dutch cabinet decided that, due to the COVID-19 pandemic, university buildings would no longer be open for teaching purposes. For Hanze University of Applied Sciences (UAS) Groningen, this meant that as of Friday March 13 and at 
least until March 31, all physical lectures and exams were suspended. This was immediately followed by the investigation of possibilities to offer lectures online so students would experience as little study delay as possible.

Uncertainty about teaching remained as the measures taken were extended and became more strict multiple times throughout the semester. During the first weeks, the prospects of offline education changed almost every other day. Eventually, universities of applied sciences decided to refrain from any physical teaching activities until June 1 . By May 8 , Hanze UAS decided to continue offering online education until the summer holidays. The government indicated that working from home remained the norm, so this also applied to all employees of Hanze UAS.

Data for this study were collected at the end of April, during the first period of the measures taken to slow down the spread of COVID-19. This stage included the rapid change to remote teaching, a period of uncertainty about how long online teaching would be necessary and whether all classes and exams would be online.

\section{Knowledge-building community}

The sharp turn to online teaching caused by the COVID-19 pandemic implies that knowledgebuilding is also digitalized. Knowledge-building emphasizes the key role of social interaction. The notion of knowledge-building is rooted in the Vygotskian view of educational dialogue (Vygotsky, 1978). From Vygotsky's sociocultural approach to learning, knowledge is socially constructed through language, and therefore educational dialogue is pivotal for knowledgebuilding.

Scardamalia and Bereiter (2003) define knowledge-building as "the production and continual improvement of ideas of value to a community, through means that increase the likelihood that what the community accomplishes will be greater than the sum of individual contributions and part of broader cultural efforts" (p. 1371). This definition implies that we advance our knowledge also using each other's ideas through educational dialogue within the community or with other communities.

In a university setting, the classroom is a small knowledge-building community. Classrooms create settings of knowledge-building where, ideally, students and teachers jointly develop their knowledge. Teachers have multiple classes and students engage in different class communities. Honors colleges and programs also offer seminars, classes, labs, and workshops which are all in themselves small knowledge-building communities.

A school community consists of a multitude of class communities. For example, Hanze UAS has 18 schools and seven multidisciplinary knowledge research centers. They are all knowledge-building communities. These communities generate knowledge jointly through within- and between-school interaction. Hanze UAS gives back to entrepreneurs and society through sharing innovative knowledge or knowledge advancement.

\section{The community aspect of a digital knowledge-building community}

The COVID-19 crisis created an unforeseen new landscape for teaching and learning with everybody involved in working at home. The sudden digitalization of our knowledge-building 
communities requires us to reshape our vision of education, community and networking aspects in particular, and think of future developments. A "new normal" will arise because of COVID-19 measures with social distancing, more online teaching, and more online meetings.

The community aspect of digital knowledge-building is a new challenge for us all, as we used to focus on the supplementary role of online learning. While there is increasing research on MOOCs (Massive Open Online Courses, see Liyanagunawardena, Adams, \& Williams, 2013), investigations about other completely digitalized knowledge-building communities are rare.

In a digital community, the traditional educational dialogue changes its form. For instance, teacher-student communication is mediated via online tools. Moreover, students suffer from pressure related to online learning. Previous peer groups such as their project team, classes, and clubs no longer meet face-to-face. They "meet" their classmates mostly as names on the attendance list in the virtual classroom. Some digital project teams are viable and ongoing; however, due to the lack of face-to-face social communication, students' learning motivation might be hindered.

Amid every crisis lie great opportunities. Facing some common problems, teachers and schools from different fields can be pulled together to solve problems collectively. In a digital community, communication and knowledge sharing can be carried out in multiple formats.

\section{The position of honors programs in digital knowledge-building communities}

An honors program as a knowledge-building community has its advantages over other knowledge-building communities, because of three reasons, as follows:

1. Often, honors consists of interdisciplinary teaching and learning and talent development projects from different schools. An honors program can work as a facilitator to pull all schools and knowledge centers together.

2. The role model effect of honors students can impact regular students to adapt themselves to online learning more effectively. They will show other students "how to learn."

3. Teacher-researchers in honors programs often had specific training and may have gotten insights into unique features of subject-related specializations in online teaching.

In this study, we were interested in how teaching and learning changed because of the required emergency remote teaching and what can be learnt from the experience to develop our knowledge-building community. Below, we share the preliminary results of our research completed after the first five weeks of the pandemic, in which the focus was on lessons learned and urgent problems to be solved.

\section{Data collection}

This study reports on teachers' and administrators' perceptions about their first five weeks of remote teaching during the COVID-19 pandemic. Since the measures were introduced quickly (see section 2), we wanted information at the start of the remote teaching period as perceptions may change over time. This study is part of a larger research project following the effects of the measures taken to slow down the COVID-19 pandemic on teaching and learning in higher education. 
Our data collection started by sending out an e-mail with questions on April 20, 2020. One reminder was sent out four days later. Most people answered our questions by email, but some preferred to talk. One of the authors called the respondents personally using the phone or Facetime/ Skype and made minutes of the conversations which were then checked by the respondent.

We asked deans, honors coordinators, and teachers five questions. Two of those questions focused on teaching:

1. After these first weeks of organizing education completely online, do you have tips that you would like to share with others so they can improve their education?

2. After these first weeks of organizing education completely online, what are the problems you would like to solve?

Additionally, we asked two questions concerning assessment, exams, and assignments. Those questions are beyond the scope of this article. The fifth question was open and allowed respondents to share experiences in general about the period with only online teaching.

We received data from 17 out of 18 schools. In total, 33 people responded. Responses were analyzed independently by the two authors and an assistant. All three used content analysis and summarized the responses. We discussed our findings and summarized them in a poster, which can be found as supplementary file to this article. We discussed the poster with respondents. We also talked about the findings with respondents and researchers of the Research Center "Talent Development in Higher Education and Society" at Hanze UAS to reach agreement on the analysis and structure of reporting.

The initial findings of the first research stage are presented in the next section. First, there is a general overview, followed by challenges and recommendations, all distilled from the responses.

In the responses, differences between teaching and learning in honors and regular education are vague - although examples of how things work well were mostly picked from honors classes.

\section{Results}

\subsection{General picture}

The general picture of the move from face-to-face education to remote teaching at Hanze UAS is positive. The most urgent problems that arose from emergency remote teaching were solved through collective efforts. Teachers were positive about digital assistance provided by Hanze UAS, calling it prompt and helpful. The main difficulties found related to technical problems students faced at home. However, some teachers faced challenges and needed to be supported and facilitated as well.

All kinds of digital tools were used - including Teams, Zoom, and Skype. The most frequently used tool was Blackboard Collaborate Ultra, which Hanze UAS provided. Teachers indicated 
that they received too many lists with tips or requests. They needed more personalized assistance - adapted to their individual questions.

Schools worked hard to offer all education responsibly and interestingly, to keep in touch with students, and to prevent study delays. Teachers and administrators seemed satisfied and proud overall. They created networks and helped each other. Knowledge networks have developed within the schools and between the schools. Deans shared evaluations and PowerPoint presentations with tips. The shared experiences gave inspiration. They thought that most students were reached and that most students could follow their courses. Although there were various problems with specific courses such as labs, internships, and competencies classes, the overall first experiences were positive. Teachers indicated that maybe even more students were in classes than in times of face-to-face education because online learning seemed less difficult to join and there was less shaming when a student was late.

It appeared that more was possible than expected. One of the teachers said: "If you had asked me in advance if I could give all honors education online, I would have said 'no' precisely because of the personal honors character. And now, after a few weeks online, things are going very well, perhaps because honors education is focused on flexibility, creativity, and proactivity."

\subsection{Challenges}

In this section we present an overview of the experiences as time progressed, as well as five challenges, distilled from the responses.

As time progressed during the first five weeks of the crisis, the disadvantages of remote teaching became more apparent: the lack of personal interaction during classes, the lack of a sense of community, and a lack of chemistry in the classroom. Initially, a crisis has occurred, and teachers and administrators needed time and help for thoughtful educational changes, innovations, and course design changes, while fatigue was also increasing.

Although nobody initially signed up for online courses, all parties involved had to do so, and some teachers could not make the switch to online. Some even questioned their professional identity. From one day to the next, teachers received an infinite amount of extra work in addition to the regular work. In their formal workload, most teachers have about 30 minutes to prepare for a one hour class - this was not enough time when everything, including assessments, had to be changed to accommodate remote teaching.

Administrators and teachers felt proud of their accomplishments since the start of the crisis. However, they expressed it was difficult to create and digitally maintain the sense of community. Administrators mentioned a wish to face the crisis professionally and to accomplish tasks. They shared new knowledge and successes but felt hesitant to share difficulties and struggles with their peers.

Teachers expressed that the lack of personal contact proved challenging. They invested in this personal contact with students in various ways, and they indicated this contact was important. However, the time investment to build personal relationships online was huge. 
Also, teaching large groups without real interaction proved doable, but tiring and less satisfactory.

Five challenges were distilled from the interviews after the first five weeks of online education:

1. New pedagogy needed

Online education and the crisis asked for "new" and different didactics, but time and skills to get acquainted with those were lacking. Interaction during classes proved difficult and teachers expressed the feeling of one-sided knowledge transfer. Deep learning, skills, and competencies such as presenting, debating, and interviewing were hard to achieve. As face-to-face encounters were not possible, it appeared difficult to connect, to ask a small question, and to feel the chemistry in your class. Personal contact or differentiation were limited .

2. Labs on hold

Some types of education asked for new solutions - and emergency remote education solutions did not always give enough satisfaction. Especially classes like lab work, competencies and skills training, medical classes, internships, and encounters with employees were difficult to replace. It was difficult to meet new people or to create new interdisciplinary classes.

3. Technical issues

There were all kinds of technical problems for both students and teachers. Also, Wi-Fi connections were often unstable, which disturbed the flow during meetings or classes. Worries about privacy issues were mentioned as well, for instance, concerning the use of Zoom.

4. Lack of connection

The feeling of connection and community was lacking during classes, for instance, because cameras were off. It was difficult to organize contact with and between students because of technical issues, bad internet, or "hiding." Also, making connections within schools and between schools asked for new solutions.

5. Workload

The workload became huge. Both teachers and administrators had changes in the content, amount, organization, and rhythm of their work. The workload may be perceived as extra heavy because everyone had to work from home. Not all could manage the change, which increased the workload for others. A need to create an individual and shared vision on the change in the near future was expressed, but time and skills to do so were lacking.

\subsection{Recommendations}

Teachers and administrators shared tips after the first weeks of COVID-19 measures for online education. We distilled five overall recommendations. 
1. Redesign

Online education should be organized differently compared to education on campus. Also, different pedagogy is needed. One could think of smaller groups and online platforms to create community. Online classes, lectures, presentations, and meetings should be shorter, as they are perceived as more intensive. The experience of social cohesion and community is important and asks for new "antennas" and different skills. Honors courses can showcase how to cocreate online education in small teams of teachers together with honors students. Also, interdisciplinary honors courses could be an example. Furthermore, a buddy system for teachers who experience difficulties with online education could be powerful. Finally, personalized faculty development could be a solution.

2. New sense of community

Pay attention to each student, if possible, individually, by creating special community moments. Do ask direct questions and ask about emotions, feelings, and experiences. Sometimes it seems easier to share personal stories or talk about (new) hobbies. Use small group coaching more frequently. Co-create courses with students. There is a risk of students dropping out, so dare to experiment in order to increase community engaged learning. Informal contact may strengthen community relationships. Student associations, mentors, or honors alumni are asked to help to increase social cohesion. Small groups are advocated. In online classes, you may consider asking students to put on their cameras and microphones. All parties' personal lives can be more present when you see each other's home situation. However, for some this can be a problem, as for students from lower socio-economic backgrounds. A way to address this challenge is to survey the students at the beginning of the course and see if they have any issues putting the camera on.

3. Networks

Enable networking. Teachers are also learning by doing. Through collaboration, new knowledge-building networks emerged, which are small, need-driven, spontaneously set up, and open. The networks are within schools and between schools. Teachers were satisfied with those self-created networks. The way they talked about those networks echoed ways knowledge-building communities are created - only now, everything happened online. Also, students can be part of those networks.

4. Structure and variety

Students benefit from structure. For instance, you can start the day together. Also, variety is important and a good balance between "sending information" and "interaction." For instance, let students prepare learning content together and use various ways to show knowledge. Provide flexibility in teaching and learning and adjust content echoing the current crisis, though learning outcomes remain unchanged. 


\section{Communication}

Clear and direct communication is crucial - between all parties involved. Provide "subtitles" during online classes to clarify emotions. Utilize personalized communication to improve student well-being and motivation. It may be helpful to facilitate sessions where students can meet each other independently without a teacher, like, for example, on Blackboard Collaborate. Some teachers started WhatsApp groups that focused on the community and wellbeing of all members. Also, communication between teachers is important, for example, to share tips and experiences. Weekly updates or online meetings can also be useful.

\section{Conclusion}

The COVID-19 pandemic caused the cancellation of all face-to-face education at Dutch universities by mid-March 2020. This study reported on experiences of teachers and administrators after the first five weeks of remote teaching and working from home.

Teachers and administrators indicated that online education is not merely moving education online. They discovered that online education provides flexibility and offers more opportunities than they thought beforehand. However, teachers missed the chemistry in class and experienced a lack of communication. They indicated that honors courses can function as an educational laboratory.

The university community had to look for new ways to improve personalized contact and interaction while face-to-face meetings were not allowed. Amidst the crisis, people helped each other and networks arose, creating digital knowledge-building communities. A next step is needed to stimulate networks aimed at strengthening the community and deepening knowledge about online teaching and pedagogies that teachers currently lack.

Teachers had to deal with a heavy workload and pressure as the quality of education must be guaranteed, even now that universities are choosing a different approach. Time was needed to recreate their courses, to re-design instructions in innovative and research-based or -informed ways, and to devise new learning environments.

The challenges and recommendations mentioned above were shared after only five weeks of remote emergency teaching. With more time, often more wisdom follows. Other potential approaches are possible than what the teachers have recommended to resolve the presented challenges. As time progresses, and the crisis continues, additional questions may be asked, for instance, about community engaged learning in a blended learning environment, new digital pedagogies for hybrid classes, and about equal opportunities and access. Furthermore, findings may have a national bias. For instance, the impact of the COVID-19-related measures on the international student body was hardly mentioned by the respondents. Also, the use of cameras and audio during classes may be interpreted differently by various nationalities or socio-economic backgrounds.

By May 2020, initial positive feelings of 'dealing with the crisis together' faded to the background, and the university community entered a new phase. Step by step, people realized that the changes and the "new situation" caused by the COVID-19 pandemic would take longer than expected and that it would be wise to create individual and shared visions 
on the "new normal." Emergency remote teaching had to transform into online education. We recommend follow-up research to map experiences during this transformation.

We propose to take advantage of shared experiences and the community building skills that were used so far. For instance, honors can showcase ways to build an open and dynamic digital knowledge-building community. In the future, when we return to our campus, we hopefully can leverage available technology to achieve effective collaboration between schools.

\section{Acknowledgments}

Thanks to our research assistant Marte Vroom and to all who participated in this study and answered so promptly despite the workload caused by measures to reduce the spread of the coronavirus.

\section{References}

Liyanagunawardena, T. R., Adams, A. A., \& Williams, S. A. (2013). MOOCs: A systematic study of the published literature 2008-2012. International Review of Research in Open and Distributed Learning, 14(3), 202-227.

Scardamalia, M., \& Bereiter, C. (2003). Knowledge-building. In: Guthrie, J. W. (Ed.), Encyclopedia of Education (2nd ed., pp. 1370-1373). New York: Macmillan Reference, USA.

Vygotsky, L. S. (1978). Mind in society: The development of higher psychological processes. Cambridge, MA: Harvard University Press. 